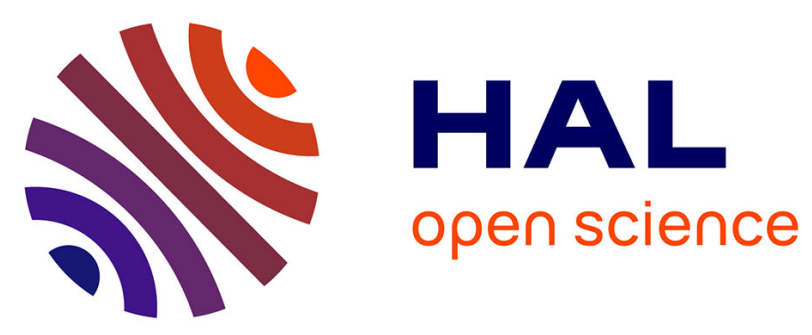

\title{
Analysis of Fretting Behavior of Silver and Gold Flashed Palladium-nickel Dissimilar Coatings for Connectors
}

Ana Torrealba, Sophie Noël, Aurore Brézard-Oudot, Antoine Fares Karam, Damien Comte, Jeffrey Toran

\section{- To cite this version:}

Ana Torrealba, Sophie Noël, Aurore Brézard-Oudot, Antoine Fares Karam, Damien Comte, et al.. Analysis of Fretting Behavior of Silver and Gold Flashed Palladium-nickel Dissimilar Coatings for Connectors. 2020 IEEE 66th Holm Conference on Electrical Contacts and Intensive Course (HLM), Sep 2020, San Antonio, United States. pp.149-156, 10.1109/HLM49214.2020.9307847 hal-03329833

\section{HAL Id: hal-03329833 \\ https://hal-centralesupelec.archives-ouvertes.fr/hal-03329833}

Submitted on 31 Aug 2021

HAL is a multi-disciplinary open access archive for the deposit and dissemination of scientific research documents, whether they are published or not. The documents may come from teaching and research institutions in France or abroad, or from public or private research centers.
L'archive ouverte pluridisciplinaire HAL, est destinée au dépôt et à la diffusion de documents scientifiques de niveau recherche, publiés ou non, émanant des établissements d'enseignement et de recherche français ou étrangers, des laboratoires publics ou privés. 


\title{
Analysis of Fretting Behavior of Silver and Gold Flashed Palladium-nickel Dissimilar Coatings for Connectors
}

\author{
A. Torrealba ${ }^{1,2}$. S. Noël ${ }^{1}$, A. Brézard-Oudot ${ }^{1}$, A. Fares Karam ${ }^{2}$, D. Comte ${ }^{2}$, J. Toran $^{3}$ \\ ${ }^{1}$ Université Paris-Saclay, CentraleSupélec, CNRS, Laboratoire de Génie Electrique et Electronique de Paris, 91192, Gif-sur- \\ Yvette, France, \\ Sorbonne Université, CNRS, Laboratoire de Génie Electrique et Electronique de Paris, 75252, Paris, France \\ ${ }^{2}$ Amphenol ICC, Besançon, France. \\ ${ }^{3}$ Amphenol ICC, Etters, PA, USA
}

\begin{abstract}
It is well known that good wear performance can be obtained with Au-flashed palladium-nickel sphere on flat contacts simulating various connector applications. It has also been shown that these good wear properties could be recorded for asymmetrical coatings such as a noble metal sphere on Auflashed palladium-nickel. In this paper we investigate the fretting properties of such asymmetrical coatings particularly of Ag versus Au flashed PdNi. The contacts are submitted to severe fretting wear by applying imposed sine displacements of amplitude similar to the Hertz contact radius. The contact resistance, the friction force and wear evolutions were analyzed and correlated to 3D profilometry measurements allowing wear volumes quantification and EDS elemental identification of the wear tracks.

Very different behaviors are observed whether the silver coating is on the sphere or on the plane though in both case the embedding of the oxidized wear debris by silver improves the fretting behavior. The transfer of silver from the sphere contact onto the palladium nickel flat is seen to be beneficial to the electrical stability of the interface for a long time, leading to more stable results than even silver/silver contacts. Nevertheless an unusual phenomenon of the galling type is observed for which more investigations are needed.
\end{abstract}

Keywords; fretting, silver, dissimilar contacts, gold flash, palladium nickel.

\section{INTRODUCTION}

The development of connected consumer devices is causing an exponential rise of the number of connector with at the same time a necessity for reliability and cost reduction. Though gold has been the favored finish for many years other alternatives have been developed, such as palladium alloys in the $80 \mathrm{~s}$ and hard silver. The concerns were mainly frictional polymer and tarnish film formation for these two types of coatings respectively but different types of processes (alloying palladium, anti-tarnish top coat), have been developed to avoid these problems [1-7]. After numerous studies to determine the performances of these coatings, gold flashed palladium nickel and hard silver have been used successfully for particular applications, often with lubrication or anti-tarnish top layers. In a work on palladium nickel [8] it is emphasized that the results in literature are difficult to use because the deposition processes have evolved and that the measurement of the accurate composition of alloys is difficult.

Palladium nickel alloy is known for good wear properties [9] but low fretting resistance [6] although some authors find a gold flash - when thick enough - to be beneficial [2, 6]. Silver coatings have good fretting properties $[4,10,11]$ but low wear resistance.

Antler's seminal work on connectors has shown in [10] that dissimilar contact pairs could be detrimental to wear and fretting behavior. It is shown that load and motion cause wear which alters the composition of the contact surface, which is the key issue in the stability of the contacts resistance. In the case of dissimilar metal pairs the type of wear (adhesive, abrasive) and the direction of transfer (if any) are permanently changing and make any modelization attempt complex or illusory.

A thin low shear film on hard contacts is known to be favorable but the wear off of such thin film is usual. Most of the reports on the good fretting properties of gold flashed palladium nickel alloys emphasize the role of the gold flash thickness.

More and more interest is shown on the subject of compatibility of dissimilar coating. The nature of the layer that predominates on the surface is crucial for the electrical behavior of the dissimilar contacts. In [12] it was shown that the fretting resistance of gold flashed palladium nickel finish is improved when in contact with a $1.2 \mu \mathrm{m}$ thick gold one because of the transfer of gold.

In [13] the durability behavior of contacts with hard pure silver and gold flashed palladium-nickel finishes was 
investigated both in symmetrical and in dissimilar configurations. The main results involve large amplitude friction simulating connector's insertion/extraction. The aim of this study is to describe and bring understanding on the contact behaviour of dissimilar pairs during fretting experiments which are known to involve more complex mechanisms. The chosen contact materials are hard silver and gold flashed palladium nickel for which no studies were found in the literature.

The questions we want to address are:

- what are the wear mechanisms involved when such dissimilar contacts are fretted?

- if transfer occurs what is its direction and what is the composition of the contact interface and its resulting effect on the contact resistance?

\section{SAMPLES AND EXPERIMENTAL TECHNIQUES}

\section{A. Samples}

Contacts will be referred to as coating1/coating2, the first being the cap and the second the flat through all the paper.

Contacts are of the sphere on flat type: the spheres are stamped in strips of CuSn6 substrate and have a radius of $1.4 \mathrm{~mm}$. A nano-crystalline nickel under layer $(1.3$ to $1.5 \mu \mathrm{m}$ thick) was first plated on the substrates. Various coatings were then electroplated on industrial reel-to-reel plating lines to allow a good reproducibility.

A palladium nickel alloy $80 \%$ wt $\mathrm{Pd}$ and $20 \% \mathrm{w} \mathrm{Ni}$ was deposited from a low ammonia plating bath. A cobalt hardened gold flash 50 to $80 \mathrm{~nm}$ thick was then electrodeposited on top. This coating is referred to as GFPdNi.

A low free cyanide silver plating bath with no alloying was used for the silver coatings. Plating parameters were adapted to obtain hard silver deposits which are referred to as HAg. They are without any top coating of any kind.

The symmetrical and dissymmetric contacts studied are described in table1.

TABLE I: THICKNESS AND COMPOSITION OF THE HAg AND GF-PdNi SAMPLES.

\begin{tabular}{|c|c|c|c|}
\hline & \multicolumn{2}{|c|}{$\mathrm{Ag}(\mu \mathrm{m})$} & $\mathrm{Ni}(\mu \mathrm{m})$ \\
\hline HAg & \multicolumn{2}{|c|}{ Cap: $4.5-5.0$} & $1.3-1.5$ \\
& \multicolumn{2}{|c|}{ Flat: $2.5-3.0$} & $1.3-1.5$ \\
\hline \hline & $\mathrm{Au}(\mathrm{nm})$ & $\mathrm{PdNi}(\mu \mathrm{m})$ & $\mathrm{Ni}(\mu \mathrm{m})$ \\
\hline GF-PdNi & $50-80$ & $0.7-0.8$ & $1.3-1.5$ \\
& & & \\
\hline
\end{tabular}

\section{B. Characterization techniques and experimental test}

Fretting tests were performed with a dedicated device involving an electro-dynamic shaker working at constant displacement. The conditions were: $\mathrm{d}=+/-25 \mu \mathrm{m}$ displacement, $10 \mathrm{~Hz}$ and normal load $1 \mathrm{~N}$. The contact radius calculated with the Hertz formulation is $25 \mu \mathrm{m}$ for the studied substrate. The tests were carried out at $\pm 25 \mu \mathrm{m}$, in order to be in fretting gross slip mode and not in reciprocating sliding mode. During the test, the voltage drop in the contact was measured with an acquisition card (333 $10^{3}$ samples/s) with a DC current value of $20 \mathrm{~mA}$ and voltage limit at $250 \mathrm{mV}$. The friction force was simultaneously recorded and a "maximum friction force per cycle" was calculated. The experiments were done at room temperature $\left(23^{\circ} \mathrm{C}\right)$ and $55 \%$ relative humidity.

The displaced matter due to deformation, transfer, particle ejection was evaluated with a Bruker Contour GT-X 3D Optical Profiler. 3D images, profiles and wear volumes were measured thanks to the dedicated software. The wear volumes were calculated for the cap $V_{\text {cap }}$ and the flat $V_{\text {flat }}$, taking into account positives volumes due to transfer and negative ones due to deformation and wear; a total wear volume for the contact was then calculated as the sum of $V_{\text {cap }}$ and $V_{\text {flat }}$.

Scanning electron microscope (SEM) images of the wear tracks were obtained with a ZEISS EVO MA10 microscope fitted with an Oxford Instruments Xmax probe for Energy Dispersive X-ray Scanning (EDS). Element mapping was performed to analyze the composition of the wear tracks and calculation of the compositions in \%at was performed for selected zones. The analyses were done at $15 \mathrm{keV}$, the depth of analysis was therefore less than $1 \mu \mathrm{m}$. Careful calibrations were performed to evaluate the accuracy of the composition calculations. For example for the 50 to $80 \mathrm{~nm}$ of gold on the palladium nickel surface the compositions were: gold: $36 \%$ at, palladium: $35 \%$ at, nickel: $26 \%$ at and oxygen: $4 \%$ at.

The thicknesses of the various layers were measured by Xray fluorescence. Care was taken in calibration. The roughness was $\mathrm{Sa}=93 \mathrm{~nm}$ and $\mathrm{Sa}=95 \mathrm{~nm}$, for $\mathrm{HAg}$ and $\mathrm{GF}-\mathrm{PdNi}$ samples respectively.

The mechanical properties of the layers (hardness and Young modulus) were measured with a $\mathrm{NHT}^{3}$ Anton Paar nanoindentor at a load of $1 \mathrm{mN}$; a large matrix of measurements was performed for each type of sample to avoid roughness influence.

The Young modulus and hardness values were measured to be: $118 \mathrm{GPa}$ and $230 \mathrm{H}_{\mathrm{V}}$ for the $\mathrm{CuSn} 6$ cuprous substrate, $194 \mathrm{GPa}$ and $330 \mathrm{H}_{\mathrm{V}}$ for GF-PdNi, $190 \mathrm{GPa}$ and $560 \mathrm{H}_{\mathrm{V}}$ for nano crystalline nickel and $107 \mathrm{GPa}$ and $125 \mathrm{H}_{\mathrm{v}}$ for hard silver.

Resistivity values were $1010^{-8}, 1.610^{-8}$ and $1410^{-8}$

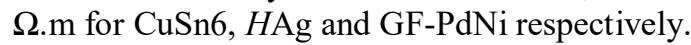

\section{RESULTS AND DISCUSSION}

The electrical behaviour of symmetrical and dissimilar contacts of Table I was assessed in long run tests; they were stopped when the resistance kept very high values for several thousands of cycles. All experiments were repeated 
several times; after observing the different behaviours the choice was made to compare contacts with the same cap finish. Fig. 1 shows the long run behaviour of $\mathrm{HAg} / \mathrm{HAg}$ contacts compared to $\mathrm{HAg} / \mathrm{GF}-\mathrm{PdNi}$ contacts and Fig. 2 compares $H \mathrm{Ag} / \mathrm{GF}-\mathrm{PdNi}$ contacts to GF-PdNi/HAg ones.

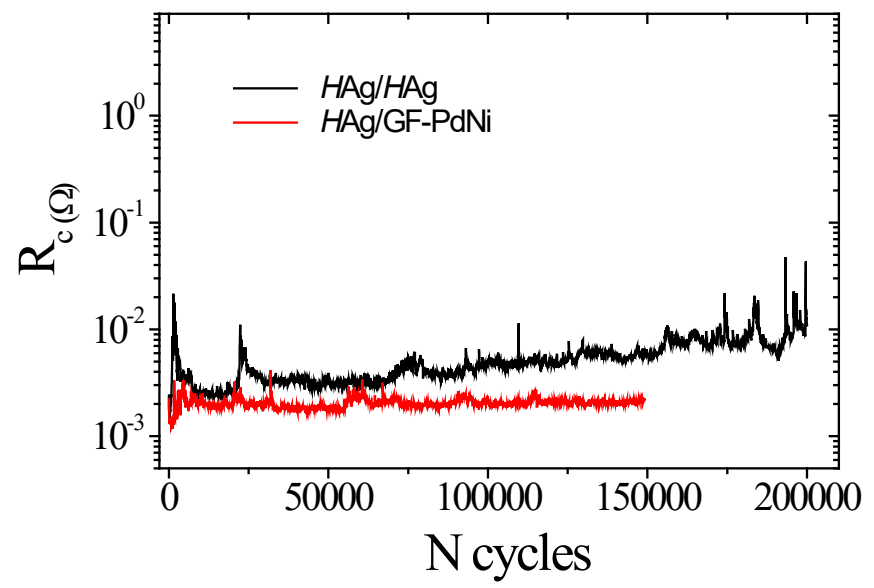

Figure 1 Mean contact resistance per cycle versus the number of cycles for $\mathrm{HAg} / \mathrm{HAg}$ and $\mathrm{HAg} / \mathrm{GF}-\mathrm{PdNi}$ contacts during fretting $(20 \mu \mathrm{m}, 10 \mathrm{~Hz}, 1 \mathrm{~N})$

The behaviour of the $H \mathrm{Ag} / \mathrm{HAg}$ contacts is described in Fig. 1 over 200000 cycles. This is a typical curve obtained several time but note that silver friction and fretting is not perfectly repeatable as it has already been reported [11]. Small increases in contact resistance ( $\mathrm{Rc}$ ) to about $10 \mathrm{~m} \Omega$ are recorded repeatedly but on the whole very little electrical degradation is recorded. The behaviour of the $\mathrm{HAg} / \mathrm{GF}-\mathrm{PdNi}$ contact does not show these small peaks of resistance and Rc remains constant during the 150000 cycles.

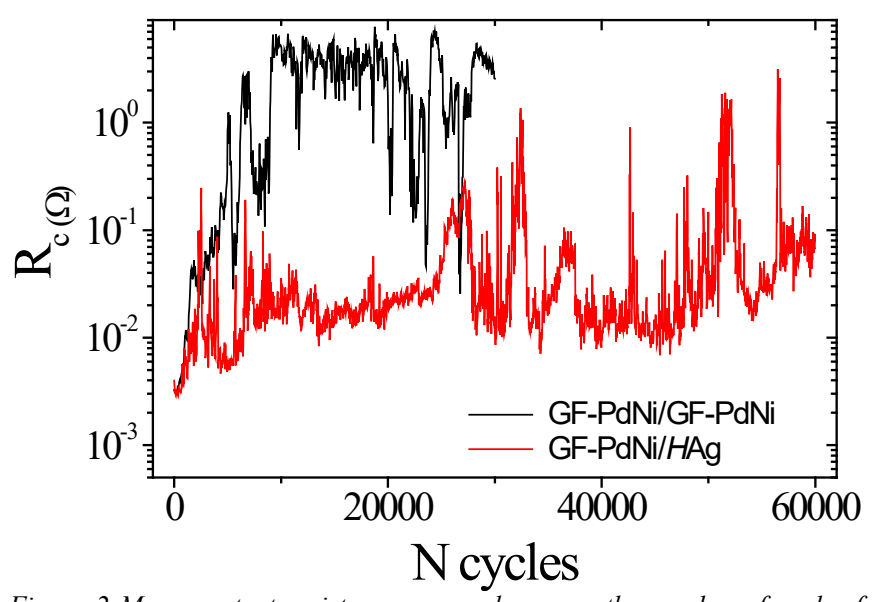

Figure 2 Mean contact resistance per cycle versus the number of cycles for GF-PdNi/GF-PdNi and GF-PdNi/HAg contacts during fretting $(20 \mu \mathrm{m}, 10 \mathrm{~Hz}$, $1 N)$

The electrical behaviour of the GF-PdNi caps on GFPdNi or $H A g$ flats is described in Fig. 2. Fretting of GF$\mathrm{PdNi} / \mathrm{GF}-\mathrm{PdNi}$ contacts is characterized by a very fast and irreversible increase of the contact resistance value. The dissimilar GF- PdNi/HAg contact evolution during fretting is characterized by fast increases of Rc followed by quick returns to lower values. The values are mostly higher than $10 \mathrm{~m} \Omega$ but the behaviour is not as catastrophic as for GF-PdNi/GF-PdNi.

To evaluate how the electrical and mechanical mechanisms take place, both the contact resistance values and the friction force ones are plotted with a zoom on the beginning in Fig. 3 and 4.

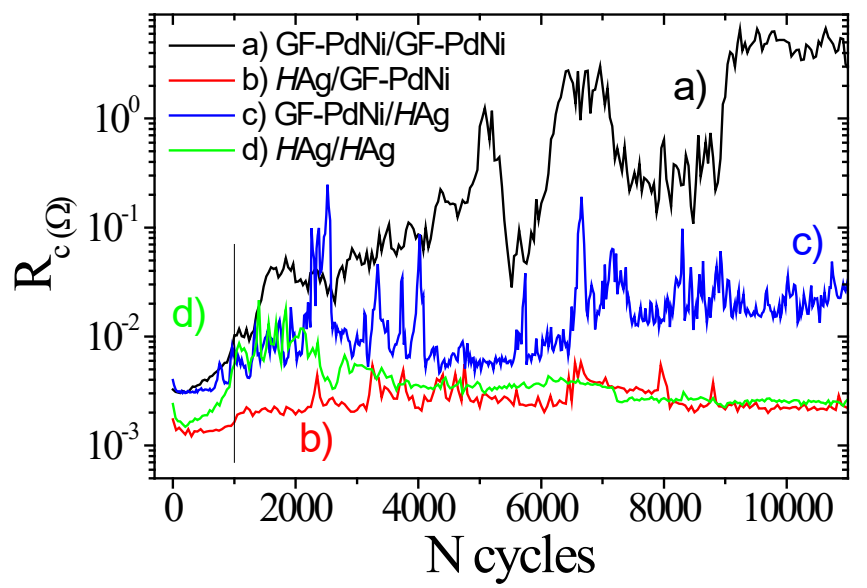

Figure 3 Mean contact resistance per cycle versus the number of cycles for $\mathrm{HAg} / \mathrm{HAg}, \mathrm{HAg} / G \mathrm{~F}-\mathrm{PdNi}, \mathrm{GF}-\mathrm{PdNi} / \mathrm{GF}-\mathrm{PdNi}$ and GF-PdNi/HAg contacts at the beginning of the fretting test $(20 \mu \mathrm{m}, 10 \mathrm{~Hz}, 1 \mathrm{~N})$

Fig. 3 shows the evolution of the contact resistance between 1 and 10000 cycles of fretting. The values of Rc at different stages of fretting are summarized in Table II.

TABLEII: SUMMARY OF THE CONTACT RESISTANCE VALUES AT DIFFERENT FRETTING STAGES FOR THE FOUR CONFIGURATIONS OF CONTACTS FROM FIG.3

\begin{tabular}{|l|c|c|c|}
\hline $\mathrm{Rc}(\mathrm{m} \Omega)$ & $1 \mathrm{cy}$ & $1000 \mathrm{cy}$ & $10000 \mathrm{cy}$ \\
\hline$H \mathrm{Ag} / \mathrm{HAg}$ & 2.4 & 5.6 & 2.5 \\
\hline$H \mathrm{Ag} / \mathrm{GF}-\mathrm{PdNi}$ & 2.3 & 1.6 & 2.2 \\
\hline GF-PdNi/GF-PdNi & 3.1 & 10.2 & 5050 \\
\hline GF-PdNi/HAg & 3.1 & 7.6 & 29.3 \\
\hline
\end{tabular}

The first observation concerns the initial values of the contact resistance which are: $3.1 \mathrm{~m} \Omega$ for GF-PdNi/GF-PdNi, $3.1 \mathrm{~m} \Omega$ for GF-PdNi/HAg, $2.4 \mathrm{~m} \Omega$ for $H \mathrm{Ag} / H \mathrm{Ag}$ and $2.3 \mathrm{~m} \Omega$ for $H \mathrm{Ag} / \mathrm{GF}-\mathrm{PdNi}$ contacts.

A quick way to evaluate the contact resistance is with the simple $\rho / 2 a$ equation. The usual calculation of the contact radius $a$ is done with the Hertz equation with the substrate parameters. Here this would give the right order of magnitude $(\sim 2 \mathrm{~m} \Omega)$ but does not account for the observed experimental values. Equation $R c=\rho(\pi H / 4 F)^{1 / 2}$ where $H$ is the hardness of the softer material can be used and gives different values.

Taking the hardness value of the softer material as silver $(\mathrm{H}=1.2 \mathrm{GPa})$ gives $\mathrm{R}=3.1 \mathrm{~m} \Omega$. This value is in agreement with the value for the GF- $\mathrm{PdNi} / H \mathrm{Ag}$ contact where the flat is $H \mathrm{Ag}$. When the hemisphere is $H \mathrm{Ag}$ coated the experimental values are lower $(\sim 2.3 \mathrm{~m} \Omega)$ which could be explained by the $5 \mu \mathrm{m}$ thickness of silver on the cap. Finally the all GF-PdNi contacts have a value of $3.1 \mathrm{~m} \Omega$ (similar to the GF- PdNi/HAg) 
maybe because of the influence of the gold layer on both the cap and the flat.

The way in which a very thin film participates to the contact physics is complex and gathering experimental data is a first step to gain some insight.

Fig. 4 shows the maximum friction force per cycles: at the beginning of the test a very strong and sharp friction peak $(2 \mathrm{~N})$ is observed for $H \mathrm{Ag} / \mathrm{HAg}$ contacts while for the GF-PdNi/GF-PdNi contact no peak is recorded and the friction force is very low friction $(0.4 \mathrm{~N})$ and almost constant. The dissimilar contacts display a smaller peak $(\sim 1 \mathrm{~N})$ that decreases after about 1000 cycles. The peak corresponding to the $\mathrm{HAg}$ cap on GF-PdNi flat seems to be sharper than the GF$\mathrm{PdNi} / \mathrm{HAg}$ one probably due to the larger amount of silver that can be deformed.

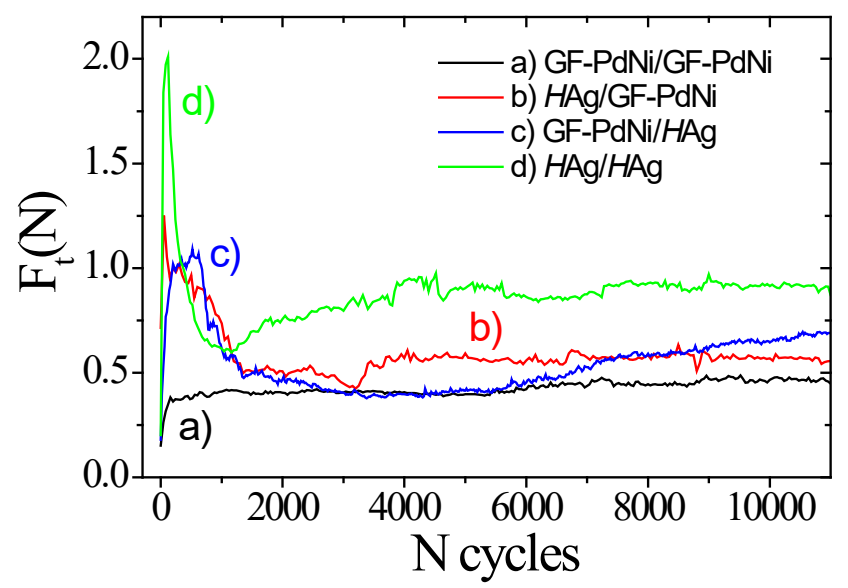

Figure 4 Maximum friction force per cycle versus the number of cycles for $H A g / H A g, H A g / G F-P d N i, G F-P d N i / G F-P d N i$ and GF-PdNi/HAg contacts at the beginning of the fretting test $(20 \mu \mathrm{m}, 10 \mathrm{~Hz}, 1 \mathrm{~N})$

Both the friction and electrical behaviours of the dissimilar contacts are different whether the cap or the flat is HAg.

Many fretting runs were performed and stopped at various numbers of fretting cycles so that the friction scars could be observed by profilometry, SEM and EDS.

In the next section we investigate the topographies and the compositions of the caps and the flats after 1000 fretting cycles in order to understand the beginning of the evolution of the contact resistance values.

Fig. 5 shows the 3D images after 1000 fretting cycles for the four configurations, the first line for $H \mathrm{Ag} / H \mathrm{Ag}$ and $\mathrm{HAg} / \mathrm{GF}-\mathrm{PdNi}$, the second one for GF-PdNi/GF-PdNi and GF$\mathrm{PdNi} / \mathrm{HAg}$. Wear can be characterized by removal of material from the contact area or by addition of transferred material into the contact area.

Both cap and flat are shown for a configuration; the caps have been flattened with the dedicated software.

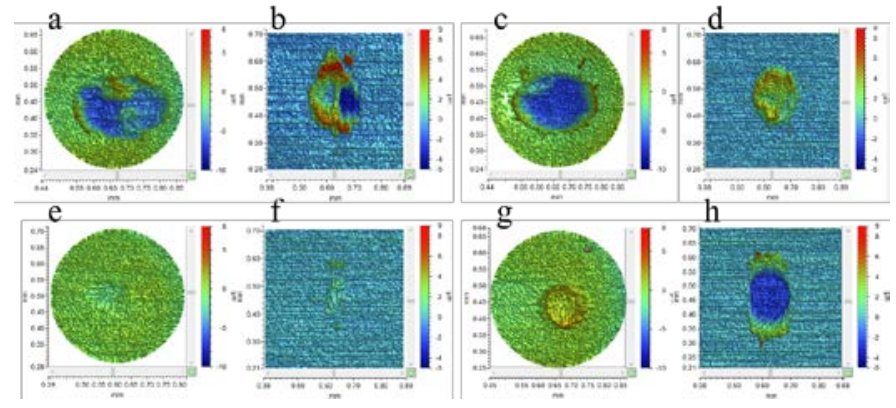

Figure 53 profilometric images of the fretting scars after 1000 cycles for: a) and b) $\mathrm{HAg} / \mathrm{HAg} \mathrm{cap}$ and flat, c) and d) $\mathrm{HAg} / \mathrm{GF}$-PdNi cap and flat, e) and f) $G F-P d N i / G F-P d N i$ cap and flat, g) and h) GF-PdNi/HAg cap and flat.

- After 1000 cycles the HAg (a) caps show deep hollow scars and transfer on the flat (b).

- GF-PdNi/GF-PdNi contacts display barely any scars and GF-PdNi/HAg contacts show transfer onto the cap and wearing of the flat.

We observe that dissimilar contacts of $\mathrm{HAg}$ and GF$\mathrm{PdNi}$ behave very differently whether the cap is a GF-PdNi coating or an HAg one. This is correlated to the Rc values: $\operatorname{Rc}(1000)=1.6 \mathrm{~m} \Omega$ for $H \mathrm{Ag} / \mathrm{GF}-\mathrm{PdNi}$ and $\operatorname{Rc}(1000)=7.6 \mathrm{~m} \Omega$ for GF-PdNi/HAg.

To assess the evolution with the number of cycles the wear volumes have been measured on both the caps and the flats. They are displayed in Fig. 6 for the $H \mathrm{Ag} / H \mathrm{Ag}$ and $H \mathrm{Ag} / \mathrm{GF}-\mathrm{PdNi}$ contacts. For the $H \mathrm{Ag} / H \mathrm{Ag}$ contacts the caps always lose material; the flats show positive wear (transfer) on the wear scar till 60000 cycles. After that, both the cap and the flat lose material probably as ejected debris. At higher numbers of cycles the debris in the interface can become a harder less ductile third body. Note that at 200000 cycles the wear is the same on the flat and on the cap.

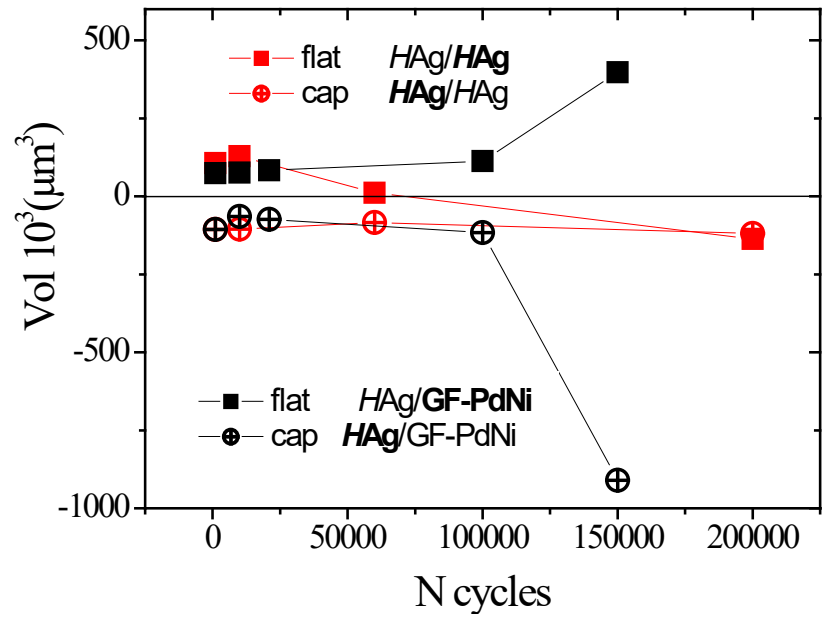

Figure 6 Wear volumes for the caps and the flats versus the number of fretting cycles; $\mathrm{HAg} / \mathrm{HAg}$ and $\mathrm{HAg} / \mathrm{GF}-\mathrm{PdNi}$ contacts.

For the $H \mathrm{Ag} / \mathrm{GF}-\mathrm{PdNi}$ contact the caps always lose material and the flat always gain material. Note that for 
150000 cycles there is a very large difference in the amount of transferred material on the flat and the amount of lost material.

Fig. 7 shows the evolutions of the wear volumes for the GF-PdNi/GF-PdNi and GF-PdNi/HAg contacts. For the symmetrical GF-PdNi/GF-PdNi contact the caps always lose material. Some transfer is observed on the flats at 1000 cycles and then the flats also lose material. Note that volume lost on the flat is much smaller than on the cap.

For the GF-PdNi/HAg contact the cap gains material during the first 10000 cycles and then both sides of the contacts lose material. At 60000 cycles the flat and the cap lose the same amount of material.

This allows knowing the direction of the transfer and additional information is given by plotting the total volume of wear for the contact such as in Fig. 8 for contacts with an $H A g$ cap. It can be seen that the total wear for $H \mathrm{Ag} / \mathrm{HAg}$ contacts is rather high $\left(20010^{3} \mu^{3}\right)$ at the beginning and then diminishes to $10^{3} \mu \mathrm{m}^{3}$ (60 0000 cycles). During this period of time the Rc values increase intermittently to about $10 \mathrm{~m} \Omega$; after 60000 cycles the Rc values increase slowly and the wear volume stays about constant over 200000 cycles.

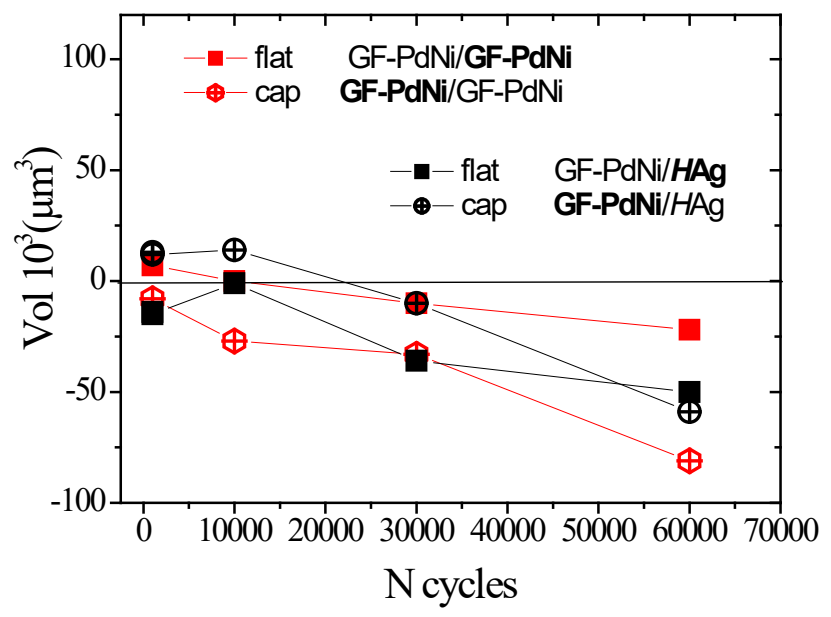

Figure 7 Wear volumes for the caps and the flats versus the number of fretting cycles; GF-PdNi/GF-PdNi and GF-PdNi/HAg contacts.

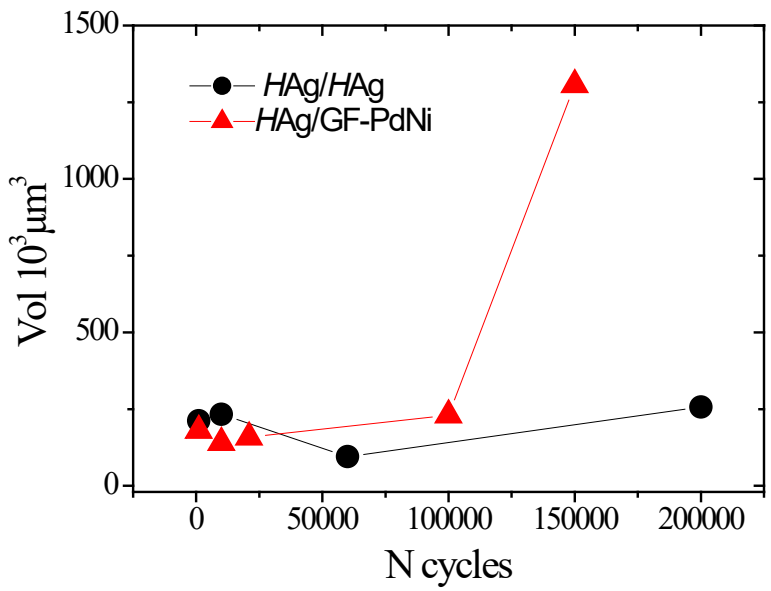

Figure 8 Total wear volumes versus the number of fretting cycles for $\mathrm{HAg} / \mathrm{HAg}$ and $\mathrm{HAg} / \mathrm{GF}-\mathrm{PdNi}$ contacts.
For the $H \mathrm{Ag} / \mathrm{GF}-\mathrm{PdNi}$ contact the total wear volumes has about the same value but increases by more than a factor of 5 between 100000 and 150000 cycles while the contact resistance remains the same $(2.7 \mathrm{~m} \Omega)$.

At the same time there is no evidence of degradation of the electrical properties for $\mathrm{HAg} / \mathrm{GF}-\mathrm{PdNi}$ contacts.

Fig. 9 displays the total wear volumes of GF-PdNi caps on GF-PdNi or HAg flats. Much smaller volumes of wear are recorded (from 10 to $10010^{3} \mu^{3}$ ); these values slowly increase with the number of cycles. The behaviour is about almost the same for both configurations of contacts while their electrical properties are very different.

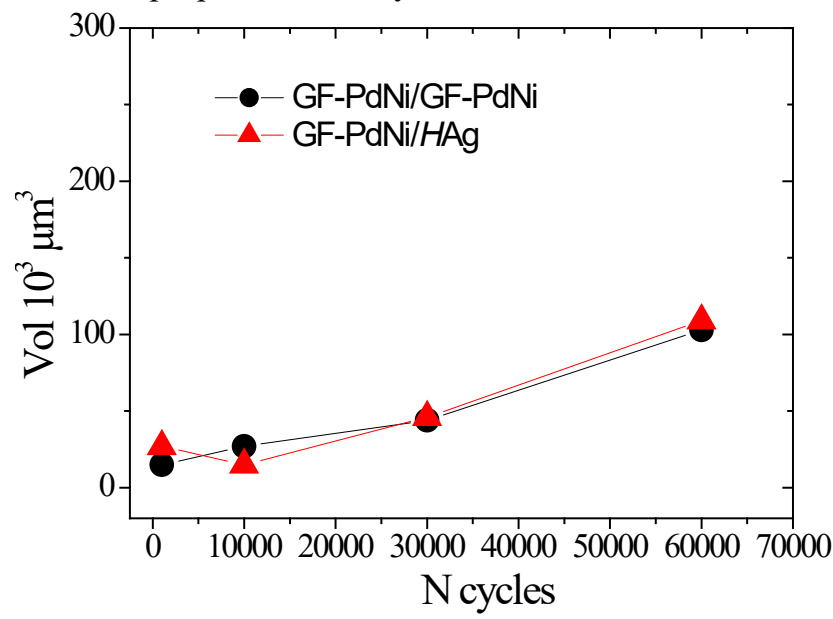

Figure 9 Total wear volumes versus the number of fretting cycles for GFPdNi/GF-PdNi and GF-PdNi/HAg contacts.

All the caps and flats at different stages of fretting were observed by SEM and analysed by EDS. Maps showing elements were acquired and composition was calculated on carefully selected areas corresponding to the wear tracks. From all these maps several were selected, described below and analysed in correlation to the wear volumes.

Fig. 10 shows the element maps (cap and flat) of the $H \mathrm{Ag} / \mathrm{HAg}$ contact after 1000 fretting cycles. Both the cap and the flat show that nickel is present in the track - either due wear off (of the cap) or wear off and pile-up on the flat. Note that the nickel exposed on the cap is not yet oxidized while both metallic nickel and oxidised nickel are detected on the flat as shown in zone a) and b) respectively.
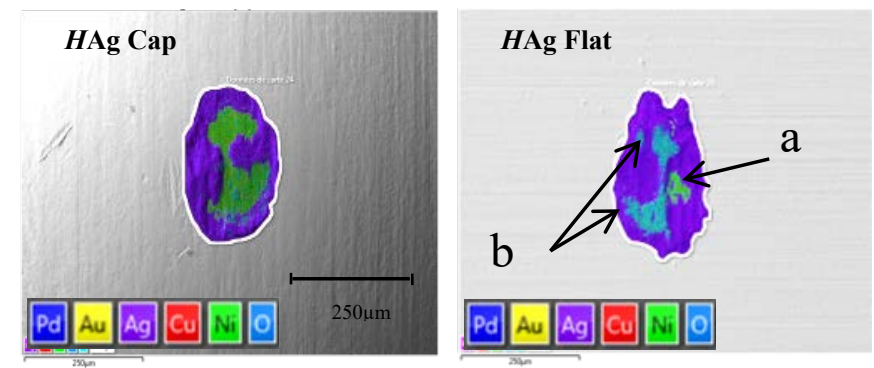

Figure 10 EDS maps of $\mathrm{HAg} / \mathrm{HAg}$ contacts after 1000 fretting cycles $(R c=5.6 m \Omega)$. 
The analysis performed after 10000 cycles are different: the wear scars show less exposed nickel spots (Fig. 11). All the composition data (in \%at) are shown in [13]. We have chosen to show here the evolution of the silver $\%$ in the wear tracks as plotted in Fig. 12.
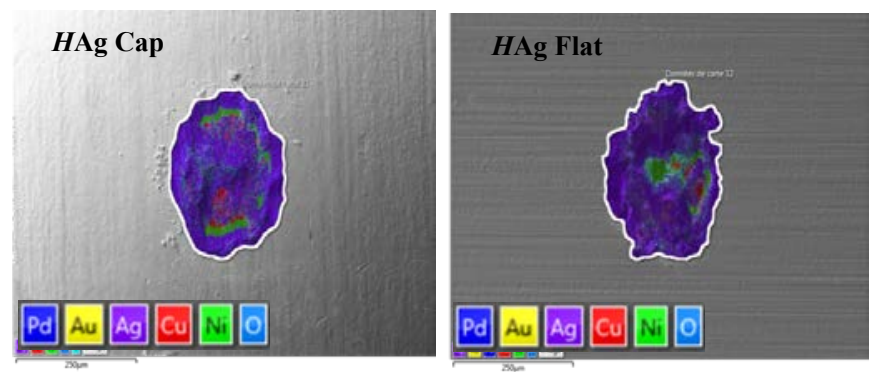

Figure 11 EDS maps of $\mathrm{HAg} / \mathrm{HAg}$ contacts after 10000 fretting cycles $(R c=2.52 m \Omega)$.

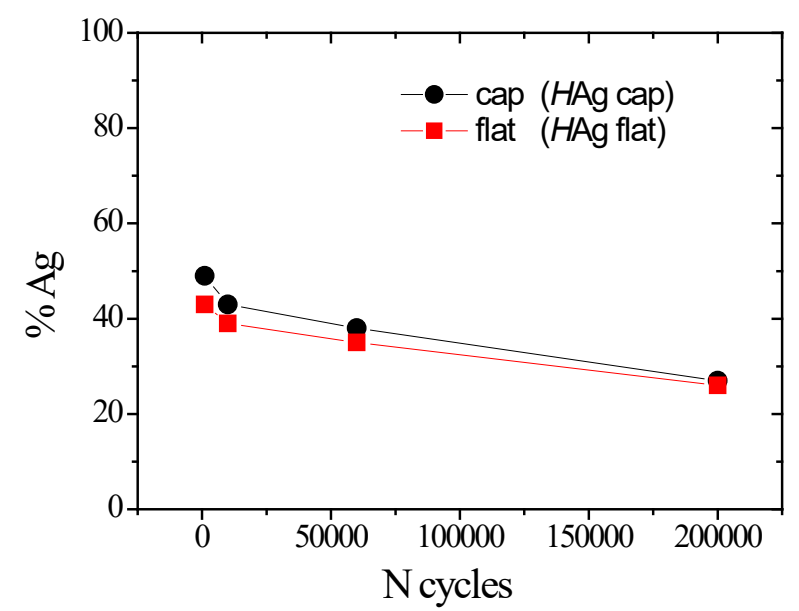

Figure $12 \%$ silver in the wear scar versus the number of fretting cycles for the cap and the flat of $\mathrm{HAg} / \mathrm{HAg}$ contacts

The \% silver decreases when the quantities of nickel, oxygen and eventually copper increase. For $\mathrm{HAg} / \mathrm{HAg}$ the $\%$ of silver in the wear tracks remains above $20 \%$ for the cap and the flat till 200000 cycles; though the Rc values rise slowly in this laboratory fretting test it is not indicative of drastic failure.

The fretting scars for $\mathrm{HAg} / \mathrm{GF}-\mathrm{PdNi}$ are shown in Fig. 13 for 1000 cycles: the transfer of silver from the cap to the flat is well observed. After 10000 cycles, Fig. 14, some silver is transferred back onto the cap. The \% of silver is plotted in Fig. 16 and up to 60000 it is around 40\%. Finally at 150000 cycles (Fig. 15) the silver \% drops because the copper $\%$ is about $40 \%$. This is not linked to a contact resistance increase because it is assumed that a mixture of gold copper and silver is formed following a phenomenon of "galling". Galling is known to be due to strong adhesion between surfaces; unlike cold welding which is often associated with vacuum or high loads, galling can occur at microscopic scale and involves mechanically assisted surface diffusion. It does not exclude motion as in the present case.

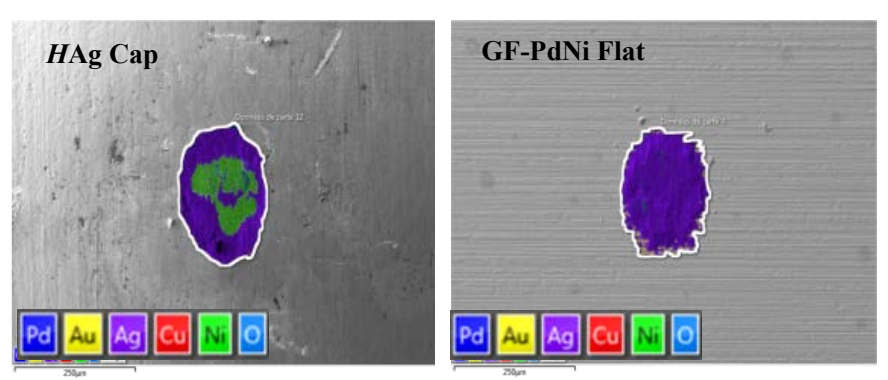

Figure 13 EDS maps of HAg/GF-PdNi contacts after 1000 fretting cycles $(R c=2.1 \mathrm{~m} \Omega)$
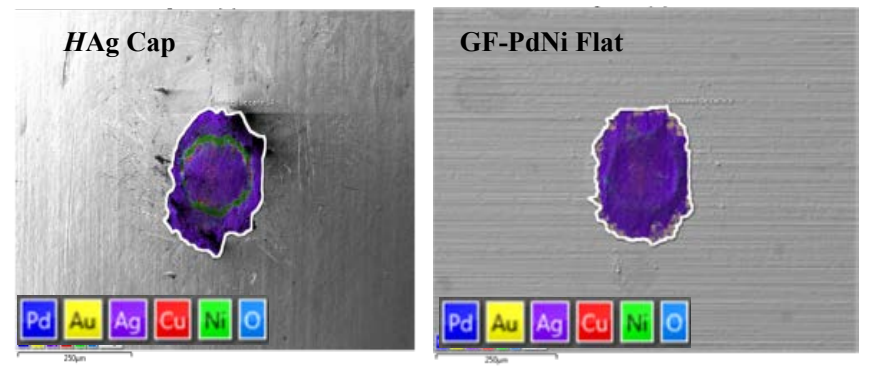

Figure 14 EDS maps of HAg/GF-PdNi contacts after 10000 fretting cycles $(R c=4.8 \mathrm{~m} \Omega)$
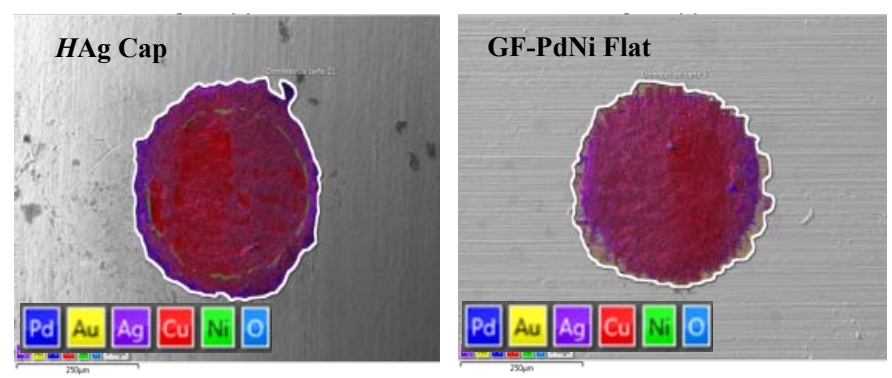

Figure 15 EDS maps of $\mathrm{HAg} / G F-P d N i$ contacts after 150000 fretting cycles $(R c=2.2 m \Omega)$

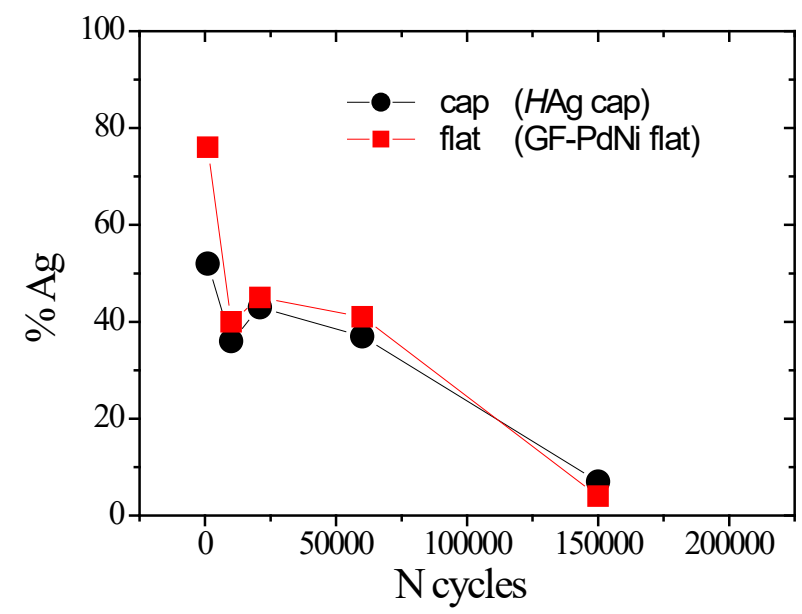

Figure $16 \%$ silver in the wear scar versus the number of fretting cycles for the cap and the flat of $\mathrm{HAg} / \mathrm{GF}-\mathrm{PdNi}$ contacts

Fig. 17 shows an element map for GF-PdNi/GF-PdNi after fretting for 30000 cycles; it is typical of all the maps observed for this type of contacts. As abrasive wear occurs the 
evolution of the composition of the wear tracks - as the number of fretting cycles increases - shows the decrease of palladium and the increase of nickel and copper; Both copper and nickel are oxidized and probably present in the wear tracks as poorly conducting debris. The contact resistance rises quickly and irreversibly as this accumulation of oxidized debris covers the contact surface.

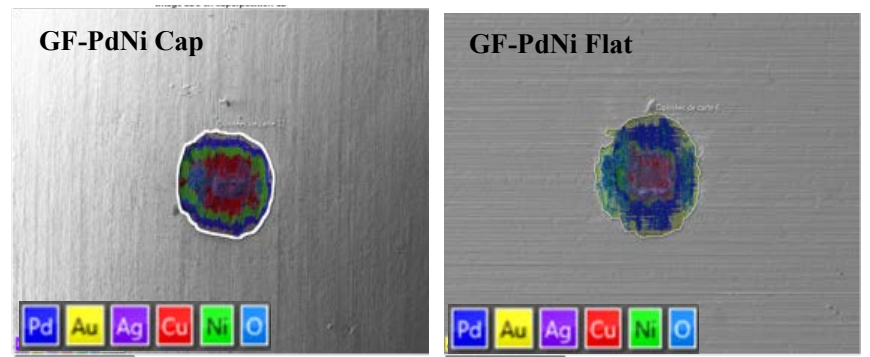

Figure 17 EDS map of GF-PdNi/GF-PdNi contacts after 30000 fretting cycles $(R c=2.7 \Omega)$

The EDS maps of GF-PdNi/HAg contacts after fretting are shown below. Fig. 18 shows that after 1000 fretting cycles the GF-PdNi caps wear scar is mainly silver from the flat. The $\%$ of silver at this point is $74 \%$ on the cap and $67 \%$ on the flat. The contact resistance value is higher $(\mathrm{Rc} 1000=7.6 \mathrm{~m} \Omega)$ than at the beginning of the run but the high percentage of silver prevents it from rising quickly.

Fig. 19 after 10000 cycles shows the transfer of silver occurs in both directions from one part of the contact to the other. The composition of silver \% plotted Fig. 21 shows a strong decrease of silver ( $20 \%$ at 10000 cycles) but enough is still inside the surface of contact to allow a value of resistance of $29 \mathrm{~m} \Omega$. Large fluctuations of the contact resistance were shown in Fig. 2 but even after 60000 cycles its value is about $68 \mathrm{~m} \Omega$ which is several orders of magnitude lower than for GF-PdNi/GF-PdNi contacts. Fig. 20 shows the elements inside the wear tracks: much copper is seen on the cap wear track and some on the flat on. Never the less the small quantity of silver plotted in Fig.21 (3\% for the cap and $12 \%$ for the flat) is enough to avoid a drastic increase by allowing some conducting paths through silver (the oxidized debris are embedded in some silver).

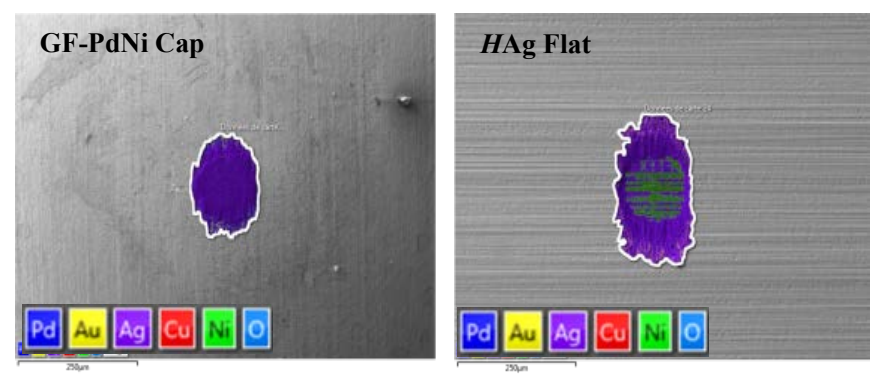

Figure 18 EDS map of GF-PdNi/HAg contacts after 1000 fretting cycles $(R c=7.2 \mathrm{~m} \Omega)$

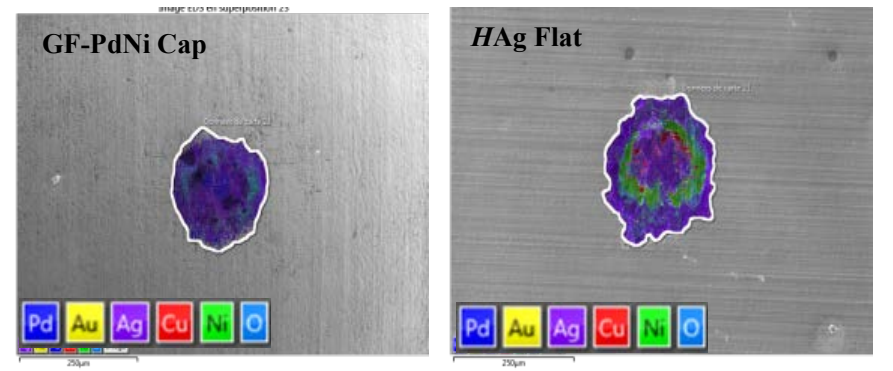

Figure.19 EDS map of GF-PdNi/HAg after 10000 fretting cycles $(R c=5.3 \mathrm{~m} \Omega$ )

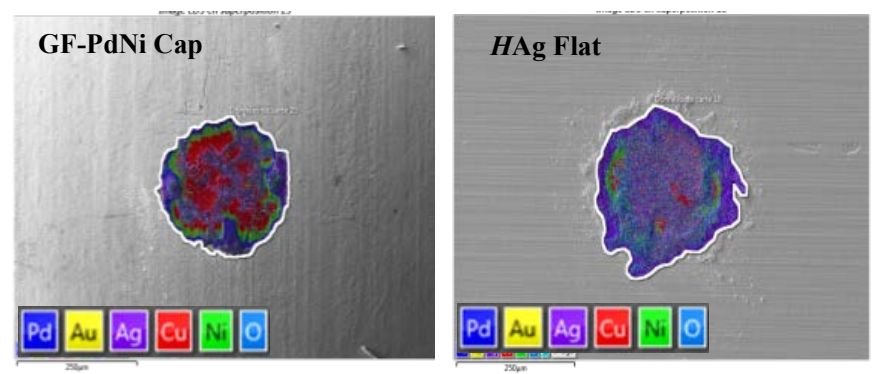

Figure 20 EDS map of GF-PdNi/HAg contacts after 60000 fretting cycles $(R c=67.8 m \Omega)$

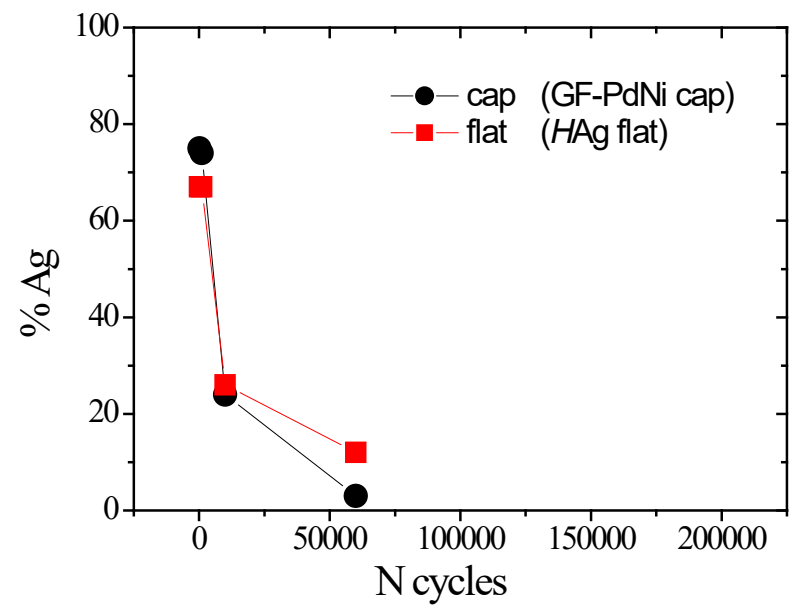

Figure $21 \%$ silver in the wear scar versus the number of fretting cycles for the cap and the flat of $\mathrm{GF}-\mathrm{PdNi} / \mathrm{HAg}$ contacts

\section{CONCLUSION}

This work is a continuation of work on durability of dissimilar contacts involving bare silver and bare gold-flashed palladium nickel coatings. It focuses on the fretting properties of these coating configurations. Some insight is brought on the behavior of pure hard silver without any protective coating in severe fretting conditions. It is shown that deformation of the silver layer and adhesion can expose the nickel under layer at times but that a high quantity of silver remains in the contact surface allowing very delayed electrical degradation.

Configurations of dissimilar contacts involving silver coating on one of the contact and gold-flashed palladium nickel have a better behavior than the symmetrical contacts. 
When the flat coating is silver and the cap one is gold flashed palladium nickel reasonably low resistance increase is observed during fretting due to the embedding of the poorly conducting debris in silver.

When the cap coating is silver and the flat one is gold-flashed palladium nickel, strong adhesion occurs. Transfer of silver onto the flat is observed followed by the formation of an alloy type material composed of silver-gold and copper which remains in the contact interface during the fretting cycles until accumulated stresses cause a galling phenomenon exposing the copper substrate. This could be avoided for example by the use of a lubricating coating diminishing the adhesion: future work will investigate such path.

\section{REFERENCES}

[1] M. Antler, "Fretting of electrical contacts: An investigation of palladium mated to other materials", Wear, 81, 1982, pp.159-173.

[2] M. Antler, "The application of palladium in electronic connectors", Platinium Metals Rev., 26,3, 1982, pp.106-117.

[3] J. P. Bare, A. M. Graham, "Connector resistance to failure by fretting and frictional polymer formation", Proc. $31^{\text {st }}$ IEEE Holm Conference, Chicago, USA, 1985, pp.147-155.

[4] M. Antler, "Contact fretting of electronic connectors", IEICE TRANS ELECTRON., VOL.E82-C, NO.1 Jan 1999, pp.3-12.

[5] P.W. Lees, P, D.W.M. Williams, "Fretting behaviour of gold flashed palladium, palladium nickel and palladium silver contact materials", Proc. $37^{\text {th }}$ IEEE Holm Conference 1991, Chicago, U.S.A., 1991, pp. 203-215.

[6] C. Morse, N. Aukland, H. Hardee, "A statistical comparison of gold and palladium-nickel plating systems for various fretting parameters", Proc. $41^{\text {st }}$ IEEE Holm Conference, Montreal, Canada, 1995, pp.33-51.

[7] N. Aukland, H. Hardee, A. Wehr, S. Brennan, P. Lees, "An examination of the metallic bonding of a clad material and two gold plating systems under contact force fretting conditions", Proc. $43^{\text {th }}$ IEEE Holm Conference, Philadelphia, USA, 1997, pp.7-19.

[8 M. Myers, "Comparison of hard Au versus hard Au flashed PdNi as a contact finish", Proc. $56^{\text {th }}$ IEEE Holm Conference 2010, Charleston, U.S.A. 2010, pp.49-57.

[9] M. Myers, "The performance implications of silver as a contact finish in traditionally gold finished contact", Proc. 55 ${ }^{\text {th }}$ IEEE Holm Conference, Vancouver, Canada, 2009, pp.307-315.

[10] M. Antler, "Electrical effects of fretting connector contact material: a review", Wear, 106, 1985, pp.5-33.

[11] J. Song, V. Schinow, "Correlation between friction and wear properties and electrical performance of silver coated electrical connectors", Wear, 330331, 2015, pp. 400-405.

[12] Y.Lin, G. Luo, L. Xu, "Fretting property of asymmetrical metal contact pairs", Proc. 26th ICEC2012, Beijing, China, 2012, pp.213-220.

[13] A. Torrealba, S. Noël, A. Brézard-Oudot, A. Fares Karam, D. Comte, A. Franchini, J. Toran, Durability of some asymmetrical contact pairs for connector application, Proc. $30^{\text {th }}$ ICEC2020, 2021, Rorschach, St Gallen, Switzerland. 